Draft Chapter to appear (2011) in Discursive Perspectives in Therapeutic Practice edited by Tom Strong \& Andrew Lock, Oxford University Press.

\title{
Activity and Performance (and their Discourses) in Social Therapeutic Method
}

\section{Lois Holzman and Fred Newman ${ }^{1}$ East Side Institute for Group and Short Term Psychotherapy, New York NY}

As collaborators on the development of social therapy, Fred Newman and Lois Holzman bring different things to the task. Newman was trained as a philosopher, originated social therapy and practices it, and is a playwright and director. Holzman was trained as a developmental psychologist and psycholinguist, and practices as a teacher, trainer and researcher. Both of us write on social therapy theory/practice, sometimes together and at other times separately. When we write together, we sometimes speak in one voice and at other times in two (or perhaps more). For this chapter we decided to preserve our two voices. After a brief historical and conceptual overview of our approach, the chapter is organized as three discourses on social therapy as performance. In Discourse 1, we together introduce that topic in relation to the practice of social therapy, the teaching of it, and directing plays. Discourse 2 was written by Holzman who takes a developmental psychologist (Vygotskian) perspective. Discourse 3, written by Newman, is a concise philosophical-political characterization of social therapy's performance modality.

\section{Overview}

\footnotetext{
${ }^{1}$ Contact Information: 1holzman@east sideinstitute.org, DrFredNewman@gmail.com. See also: www.eastsideinstitute.org, loisholzman.org, www.frednewmanphd.com.
} 
Social therapy (or the broader practice/theory of social therapeutics) is an approach to human development and learning at the leading edge of the critical and postmodernist movements in psychology. It challenges, in practice and theory, many of psychology's and psychiatry's presuppositions about persons; therapy, the therapeutic relationship and therapeutic discourse; illness, cure and treatment; emotions and cognition; and mind, body and brain. This orientation locates social therapy within the diverse grouping of non-medical model approaches that identify as discursive, collaborative and/or social constructionist.

Social therapy was introduced in the 1970s by philosopher and lay therapist Fred Newman. Since then it has continuously been developed by Newman and developmental psychologist Lois Holzman into a practical human development methodology (social therapeutics) with broad application in the myriad of settings that children, youth and adults create and inhabit. As a psychotherapy, it is a positive, relational approach with special focus on emotional development and group creativity. While philosophically informed, social therapy is a practically oriented method in which human beings are related to as creators of their culture and ensemble performers of their lives (Holzman \& Mendez 2003; Newman \& Holzman 2006/1996).

Developed outside of academia at the East Side Institute for Group and Short Term Psychotherapy in New York, social therapy has been practiced since the mid-1970s in social therapy centers, clinics, schools, hospitals and social service organizations in the US and, increasingly, abroad. As a method for social-emotional growth and learning, the social therapeutic approach has impacted on education in school and outside of school, and youth development (Feldman \& Silverman 2004; Holzman 1997, 2000, 2009; 
Lobman 2005, 2010; Sabo 2007); on training and practice in medicine and healthcare (Massad 2003); and on organizational development and executive leadership (Holzman 2009; Salit 2003).

While several intellectual traditions have informed the social therapeutic approach as it has evolved since the late 1970s, the conceptual frameworks of Karl Marx, Lev Vygotsky and Ludwig Wittgenstein have been most influential. Their writings have helped us to understand both the potential for ordinary people to effect radical social change and the subjective constraints that need to be engaged so as to actualize this potential. Social therapy has evolved as an unorthodox synthesis of these three seminal thinkers.

Marx. In the works of Karl Marx, one finds a radically social humanism and methodology, especially in his early writings (for example, Economic and Philosophical Manuscripts and The German Ideology). More than his political economy, it is this that has influenced and inspired the development of social therapy (Newman 2000b; Newman \& Holzman 2003). For Marx, human beings are first and foremost social beings. He posited that both human activity and human mind are social, not just in their origins but in their content. Methodologically, the transformation of the world and of ourselves as human beings is one and the same task: "The coincidence of the changing of circumstances and of human activity or self-changing can be conceived and rationally understood only as revolutionary practice" [revolutionary, practical-critical activity"](Marx \& Engels 1974, p. 121). It is this capacity that makes individual and species development possible. 
Vygotsky. Vygotsky brought Marx's insights to bear on the practical question of how human beings learn and develop (Vygotsky 1978, 1987). It is human activity (qualitative and transformative) and not behavior change (particularistic and cumulative) that is the unique feature of human individual, cultural and species development (Newman \& Holzman 1993). Human beings do not merely respond to stimuli, acquire societally determined and useful skills, and adapt to the determining environment. The uniqueness of human social life is that we ourselves transform the determining circumstances.

Vygotsky's departure from traditional psychology's understanding of development — that it is not an individual accomplishment but a socio-cultural activity— helped us to see more clearly how our therapeutic and educational practices worked. His writings on cognitive development, play and language in early childhood have great relevance to emotional growth at all ages. Children learn and develop, according to Vygotsky through being related to as beyond themselves, and being supported to play or perform, "a head taller" than they are. We take Vygotsky to be a forerunner to a new psychology of becoming, in which people experience the social nature of their existence and the power of collective creative activity in the process of making new tools for growth (Holzman 2009, 2010; Newman \& Holzman 1993).

Wittgenstein. Ludwig Wittgenstein challenged the foundations of philosophy, psychology and linguistics. His was a radically new method of doing philosophywithout foundations, theses, premises, generalizations or abstractions. Especially important to how social therapy relates to emotional life is how Wittgenstein exposed the "pathology" embedded in language and in accepted conceptions of language, thoughts 
and emotions. His work can be seen not only as therapy for philosophers (as some have noted, e.g., Baker 1992; van der Merwe \& Voestermans 1995) but also for ordinary people. For, by virtue of the complicated network of social, communicative institutions that have evolved since human beings invented language, versions of philosophical pathologies permeate everyday life and create intellectual-emotional muddles. In Unscientific Psychology: A Cultural-Performatory Approach to Understanding Human Life (2006/1996), we put it this way:

His self-appointed task was to cure philosophy of its illness. (Ours, as we will try to show, is closer to curing "illness" of its philosophy.) We are all sick people, says Wittgenstein. No small part of what makes us sick is how we think (related in complicated ways to what we think and, even more fundamentally, to that we think or whether we think), especially how (that or whether) we think about thinking and other so-called mental processes and/or objects - something which we (the authors) think we (members of our culture) do much more than many of us like to think! It gets us into intellectual-emotional muddles, confusions, traps, narrow spaces; it torments and bewilders us; it gives us "mental cramps." We seek causes, correspondences, rules, parallels, generalities, theories, interpretations, explanations for our thoughts, words and verbal deeds (often, even when we are not trying to or trying not to). But what if, Wittgenstein asks, there are none? (Newman \& Holzman 2006/1996, p. 174). 
Indeed. Nearly all therapies, whether Freudian, neo-Freudian or cognitive-behavioral, begin with the assumption that certain kinds of physical acts of the individual have a causal connection to certain kinds of mental acts of the individual. Social therapy does not. Instead, inspired by Vygotsky, but developed well beyond his writings (which were not therapeutic), social therapy works with the notion that there is not so much a connection but a non-causal connectedness between so-called mental acts and physical activity. Vygotsky's word for this (translated from Russian into English) is "completion" (Vygotsky 1987). His radical challenge to both pictorial and pragmatic views of language, and the understandings of the thought-language relationship that follow from these views, was that thoughts are completed—not expressed—in speaking (and other actions).

The structure of speech is not simply the mirror image of the structure of thought. It cannot, therefore, be placed on thought like clothes off a rack. Speech does not merely serve as the expression of developed thought. Thought is restructured as it is transformed into speech. It is not expressed but completed in the word. (Vygotsky 1987, p. 251)

This non-expressionist conception of thinking/speaking as a dialectal unity (a non-causal connectedness) is, theoretically, in the best sense of the word, at the very core of social therapy. Causal connection, or what is known in the philosophy of science as deductive connection, is what social therapy has tried to move beyond in finding a foundation for a genuinely humanistic therapy. 


\section{Discourse 1}

\section{by Holzman and Newman}

While social therapy can be counted among the discursive therapies, it is historically (and discursively) rooted in an activity theoretic and a performance ontology. Marx's understanding of activity and dialectics has been important in the development of social therapy since its beginnings over three decades ago, followed closely by Vygotsky's application of these aspects of Marx to psychology (especially human development and learning and the role of play in both). Performance, and more generally the language of the theatre, began to occupy a prominent place in our work a bit later, about twenty years ago. The creativity that is entailed in both activity (and its discourse) and performance (and its discourse) — as radically humanistic methodologies — has a particular intellectual and political appeal to us that "discourse" and "talk" talk do not. (Both of us have studied language, discourse, talk, communication, conversation, etc. fairly extensivelyHolzman within the discipline of linguistics/psycholinguistics and Newman within the discipline of philosophy of language/science.)

With that said, social therapy is the social-cultural-historical activity of groupings of people collectively creating environments in which they can and do perform therapy. They create both the environment and the performance simultaneously. Therapeutic talk, in social therapy as in all discursive therapies, begins as individuals telling their stories. The work of social therapy is to transform the culturally and institutionally overdetermined psychological and truth-referential environment-and-talk into a "theatre 
without a stage" upon which the therapy group, qua group, creates a play (in this case, their therapy play).

Why? Because we are interested in human development and engage in activities that we believe help people to grow and transform qualitatively. Theatre and therapy can be developmental/transformative because both are opportunities for people to experience life in new ways, in ways other than those we have been socialized to-i.e., without a problem-solution or conflict resolution paradigm, but rather seeing life's uncertainty and unknowability.

Newman is a playwright who has written over thirty plays and directed many of them, as well as those of the late avant-garde East German playwright Heiner Müller. As therapist and theatre person, he has a particular take on the social therapy play (which is, perhaps, applicable more generally to the theatricality of therapy and the therapeutics of theatre).

Let's hear from him:

"I try to create plays at which my ideal audience member walks out of the play and says, 'What in the hell was that?' I've been doing group therapy for 35-40 years now and, as far as I can tell, that's what the people whom I work with walk out of every session saying. Because every session is a play. It's a play that we create together. Sometimes people walk out and say, 'Oh I got it,' and then someone else from the group usually helps me by saying, 'What are you talking about? What do you mean you got it? If you got, you don't get it.'

That human process of not just questioning ourselves, but of not knowing —of allowing ourselves to stop thinking that we know what's going on, and instead simply 
have the kind of social experience that is poetic and growthful and developmentalmakes us more human.”

What is a poetic and growthful and developmental social experience? Over the years we have come to identify it in simple (to say, not to do) terms-it is the activity of creating something new out of what exists. This is not, we suspect, very controversial. Where it becomes so, in our experience, is in the nature of "what exists" and what is usable to create with. In therapy, what exists is what people bring to each session, which is typically their problems, pain, hurt, victimization, depression, insecurity, fears, and so on (inseparable from their ways of talking and their stories about them). The social therapeutic task is to create something out of all this ugly stuff, to transform it - not narratively but performatorily. The difference is, we believe, big. Social therapists are not working with clients to make the ugliness go away or to create a prettier or better story of their lives. They are, instead, working with clients to give their ugliness/their stories to the group as material with which to create the therapy (play).

Newman and I have discussed this distinction relative to theories of language and therapeutic approaches (see Holzman, 2009; Newman, 2000a; Newman \& Holzman, 1999; Newman \& Holzman, 2006/1996). Here we use some of our experiences to highlight the performatory nature of therapeutic creativity as we understand it in our work.

First, Newman's experience directing Heiner Müller's Hamletmachine sparks some comparisons with doing social therapy.

“In the play Müller writes of 'lugging his overweight brain'—a beautiful, if ghastly, poetic image. Postmodernism, the overly intellectualized effort to move beyond 
modernism, is surely lugging modernism's overweight brain. And indeed, so is Müller, the brilliant poet, lugging his overweight brain. Müller is one of the great brains of the $20^{\text {th }}$ century, yet from the vantage point of lugging, it is merely overweight. His brain is a cancer and it killed him long before his death. The work that I try to do hopes to revive him not simply by doing his plays, but by doing something with his plays. To me, theatre is as least as much a way to help people grow as therapy is. I'm trying to get Heiner Müller to grow because I think his work is brilliant in the spirit of deconstruction that calls out to destroy everything. That touches me and I think that's marvelous. My own vision, in psychology as well as in theater, is to take what's being destroyed, what's being smashed into a million pieces, and create something with it. So Müller is someone whom I feel very close to because he makes it possible for there to be something for me to work with. He destroys everything. My concern is to build with all the garbage, with all the crap. That's my theatrical, poetic vision - to take the garbage of the world and not make it look good, not put a lot of fancy smelling stuff on it or shape it up, not to do what's done on Broadway where crap is made to look beautiful and therefore mislead people and mis-teach people politically. What I try to do is political theater that shows that we have to learn how to create with the crap that we have inherited. Because this is our working material. And no mental act, in my opinion, can turn crap into anything but crap, though we can create with it as the material.

That's what therapy is all about. That's what people bring into therapy after all, and it is what we expect them to bring in. They bring in that which has been destroyed, which they call by various names, but fundamentally they call it 'my life.' They bring in their pain, their destroyed lives, their destroyed visions. They bring these lives into a 
therapy room and they share them with other people in the group in what I think is a wonderful act of love. And then we take that terrible, ugly stuff, which is for all of us in varying degrees who and what we are, and the work I try to do is to help people create something out of that. 'Let's build something with that.' And that's a play. That's as much a play as anything I put on the stage. Social therapy groups are fantastically interesting plays — week after week a different play. The only difference is that we don't sell tickets to watch them and we don't do a video of them. But they're plays."

As a trainer and teacher, I (Holzman) work social therapeutically to create something new out of what exists. Often the topic and substance of what I'm training people in or teaching is social therapy, which means that people are involved in learning social therapeutics - the method—social therapeutically. The class or workshop (the group) has to create the learning environment by using "what exists" (the material, their histories, responses, understandings, and so on) in order to learn (about) the method. They are creating, in Vygotsky's words, "simultaneously the tool and the result" (Newman \& Holzman 1993; Vygotsky 1978).

This raises some similar and some different issues from the therapy activity. The desire to "get it" is similar — and in an educational setting to be asked to suspend this goal can be particularly frustrating for some. An individualistic bias/strategy is operative as well. Going into therapy, the working assumption is that the way to get help is to talk about oneself; in the case of students entering classes and seminars, they are consumed with what they themselves will get out of it. Unlike in therapy, where people expect to talk about how they are feeling, educational settings are generally constructed as emotion-free zones. One's fears of not knowing or looking stupid, competitive feelings 
towards others, the frustration and anxiety that accompany boredom and lack of concentration - all these and more are not usually related to as material that can be made use of in learning. All of us have been very well socialized to see therapy and education as they have been constructed through their institutional and popular discourse, which makes these working hypotheses completely understandable, and challenges to them quite a provocation.

Creating development "out of garbage" was difficult to contemplate for a group of educators and psychologists whose country had gone through an intensely violent civil war during the 1990s. In my work with them, they told painful personal stories of death, destruction, bewilderment, loss of meaning and paralysis. It seemed from the telling that they had repeated these stories very often. At the same time, when I invited them to perform their lives "on stage" they were fully and playfully creative and improvisational. Without the stage, they spoke from their scripts. The challenge was, could they create with their scripts; could they perform off the stage as well; could we play with their stories together and in doing so transform the pain they were talking about into a performed conversation, whose meaning (and meaningfulness to all) was in its creating and not in any aboutness; could we create something new with the "garbage" of the world? Raising these questions used and built with the material they had already given to the learning environment. Through this activity, we discovered together that as a group they were not willing to transform their activity from "telling the truth" about their lives into performing their lives conversationally. The group consensus was that garbage is garbage; you cannot create with it. Many of them felt that all they now had of their own 
was their pain and loss and they were not about to give it up. They would tell their story but not share it. They would narrate but not perform.

It is tempting to see this shift from talking to performing conversation in terms of scripted and improvisational performance—don't! In therapy sessions, classrooms and training workshops, we all have our roles and our lines. The social therapeutic work is to collectively take these roles and lines and in some nuanced way create something new. Again, Newman's way of understanding theatre helps make this point:

"Actors get their roles in the play. Now they know what their lines are, just as we know what our lines are in life. And the actors say those lines. But that's not the creative part of the play. The creative part of the play is what the ensemble does. The creative part is the relational part. It's how people say things to each another and exactly how people move when they say them. That's improvisational and there is tremendous variation in it. The creative and developmental element in theatre is finding a way-after you've discovered your role - to abandon your role. Learn your role well. Accept it. Internalize it. Now forget about it. You've got to go beyond it if you want to create something. Move beyond it to create. In therapy as well. We work hard to learn who is there in the therapy room in order to create something together that is bigger than any of us and what we brought in. That is a strong similarity between roles, scripts and improvisation in terms of what goes on developmentally in theatre and therapy."

\section{Discourse 2}

by Holzman 
Developmental psychology tends to relate to culture in one of two ways. Within the broad mainstream of the discipline, culture is considered to be a factor in human development, that is, something that influences the developmental process. Within constructionist and cultural-historical psychology, development is cultural, in that what it means for children to develop is that they adopt ("appropriate") the culture that they are born in to. My own perspective is that human development consists of both the appropriating and the creating of culture, and that their dialectic interplay is what is most interesting and relevant to understand. That is one way I see the social therapeutic activity of transforming narrative into performance.

Vygotsky's writings on development, learning, and play, and language and thought have shaped this way of seeing (no doubt, working with social therapy has equally, if not more, shaped how I understand his writings - the simultaneous shapings being an instance of appropriating and creating culture). These processes are, for Vygotsky, cultural-historical and collectively produced, accomplished through "a collective form of working together" (Vygotsky 2004, p. 202). Vygotsky's zone of proximal development (zpd) is for me the prime example (Holzman 1997; 2009; 2010). Young children and their caregivers together create the zone by their activity (playfully and creatively imitating and completing each other's speech, movements and actions). Before school age, children's learning is seamless with their everyday activities, which are nearly all playful. Not only do they spend a lot of time playing in the sense of what adults identify as children's play (free play, pretend play), but with caretakers and older children they also play speaking and reading and making dinner and getting dressed, etc. 
This kind of play (and, thereby, learning in early childhood) is performatory, that is, non-didactic, non-cognitively based, and non-individuated. Fifteen-month olds who do not yet know the language of their family perform as speakers of it; two-year olds who are not literate perform as readers; three-year olds who know nothing of perspective or representation perform as artists. The performatory zpd supports them doing things they don't yet know how to do; it activates what Vygotsky referred to as "the child's potential to move from what he is able to do to what he is not" (Vygotsky 1987, p. 212). In the performatory zpd children develop because they are both who they are and beyond, or other than, who they are at the same time. This is akin to Vygotsky's notion that play is developmental for children because it is when they act as if "a head taller" (Vygotsky 1978, p. 102). Perhaps the collective form of working together in early childhood is better identified as a collective form of playing together. It is a playing together in which culture (i.e., the "stage" and the performance) is created and simultaneously appropriated. With respect to language, this means that speaking as performance (performed conversation) precedes and makes possible speaking as narrative (talking about things). (While psychologists have noted that narrative is a rather late development in childhood, as far as I know they have not explored the performatory nature of pre-narrative speech.) And once narrative begins, it pretty much takes over in most people's lives. This is the socio-cultural-historical "presenting problem" for social therapy. Adults speak narratively. To grow emotionally, they need to learn how to do speaking as performance. The group needs to create a performatory zpd in which they, with the support of the therapist, can do what is beyond and not known to them (as young children do): take their ways of speaking and listening to each other - their narratives and stories and 
accountings - and use them to create a new kind of conversation, a conversation that is not merely spoken, but performed. The process of this transformation (creating the therapy play) creates in the group new ways to understand and relate to talk and to emotionality. It is emotional growth by virtue of the group growing.

\section{Discourse 3}

by Newman

In "Where is the Magic in Cognitive Therapy? (a philo/psychological investigation)," a chapter in Against and for CBT (Newman 2009), I wrote what might be the most complex sentence I ever intentionally created. I called it Sentence NAD: (Not a definition) and it goes like this:

Within a performatory (as opposed to a cognitive) modality (community), we (social therapy/social therapists) seek to help create a pointless dialectical (a mixture of Plato's and Marx's) group conversation (a conversation oriented toward discovery/creation) in order to generate a new game (a Wittgensteinian game) which completes (in a Vygotskian sense) the thinking, and is itself (by magic, a.k.a. art) a performance (though more activity than an action). (p. 229)

I didn't have the chance to unpack the sentence in that chapter, but will do so now. "Within a performatory (as opposed to a cognitive) modality (community)..." 
Much as very traditional psychoanalysis attempts to overcome this hard fact, all therapy is done in a historical spacio-temporal environment. Classical social therapy is carried out in a self-consciously organized community which could be identified as a synthesis of a 70's-style therapeutic community, a 60's-style alternative school community, an activist progressive political community, and an avant-garde political theatre community begun in the late 60 s (in the midst of the mini-upheaval that now bears the label "the Sixties").

It is now, some forty years later, of substantial size, located in various places throughout the world (plus cyberspace) with thousands of people with varying degrees of interest in one or many of its varied forms. All of those involved are hardly the same. It is not a cult. Indeed, it is not even remotely cultic. Most members of the community have no idea what other members of the community are doing. It has been designed to be (and succeeds in being) methodologically and structurally disconnected; it is what we call a practice of method (Hood [Holzman] \& Newman 1979).

That our critics persist in calling it a cult shows their need and indeed international society's need to comprehend something by way of connectedness.

“...we (social therapy/social therapists) seek to help create a pointless dialectical (a mixture of Plato's and Marx's) group conversation (a conversation oriented toward discovery/creation)..."

The classical social therapy group is roughly made up of 25 people (the more diverse, the better) who gather weekly with a therapist/leader/facilitator and an assistant. Most of the members have "been through" or are still going through individual therapy, in some cases at one of the social therapy centers. 
The group is asked to form themselves as a therapeutic environment which could help the members with their emotional problems. In almost all cases, this soft directive is misheard and seen as an opportunity for individual members to get individual therapeutic help (a relatively traditional form of traditional group therapy).

The early stages of group social therapy (perhaps years) is devoted to conversation intended to clarify this distinction. But the group (made up of individuals, after all) never quite abandons its individualistic drive. So even after years of working together, individuals in the group will attempt to come to group "seeking help" with their own problem at home, at work, with a lover, etc. As the group develops a longer history it will tend all the sooner to have a group recognition that they have gone off in the "wrong" direction. The group then returns, though often begrudgingly (and characteristically via the therapist), to collectively building an environment for helping individuals.

How is the above description pointless activity, or equivalently, how does the group do this?

This is unknown. But pointless conversation is recommended. Pointless in that the group's engagement in conversation, the activity of conversing, is what creates the group. What the group talks about makes little difference. How the group talks about it makes a great deal of difference.

Do emotional concerns tend to dominate, as opposed to, let's say, quantum physics? Yes. Unless the group happens to be made up of all and only quantum physicists (which is rare - indeed, it has never happened). But typically emotional issues will dominate. But when and if individual members slip and slide toward individual problem 
solving, the social therapist will politely (sometimes not so politely) reconvene the group as a group attempting to create an environment for helping people with their emotional problems.

Such is the performatory dialectic of the classical social therapy group. It is the dialectic of classical Marxist theory and workers seeking higher wages, the dialectic of art theory and making art, the dialectic of theory and practice.

“... in order to generate a new game (a Wittgensteinian game) ..."

Wittgenstein's notion of a "language game," which could just as easily be called a "life game," is, properly understood, central to fully appreciating postmodernism (at least in its psychological expression) for it gives performatory dominance to the ever-present activity/abstraction dialectic. Within our legitimate culture everything said is related to as both something said and something said about something. Philosophers of language have searched for exceptions but in ordinary language usage this paradigm (the denotative) dominates and with this dominating paradigm comes the corollary that what is said is more what it is about than it is the activity of saying. Wittgenstein's notion of the language game challenges this long-standing paradigm at its very heart and soul. "... which completes (in a Vygotskian sense) the thinking..."

Vygotsky, who died of tuberculosis in his thirties in the 1930s, was a brilliant Soviet psychologist with a keen and revolutionary interest in educational development. Social therapy has considered the applicability of his ideas to emotional development. Amongst the many things we have discovered in Vygotsky's writings is his recognition of and sensibility to the classical mind/body problem. Moreover, he offers a solution to it in his insistence that what the mind creates is indiscernible, separate from what the 
listener "completes" in her or his hearing. Hence, there is nothing to be connected, for discourse is essentially social.

"... and is itself (by magic, a.k.a. art)..."

Art, even in classical terms has (we believe) always been seen as the "connectedness" of the "disconnected." Science, as well, especially in late modernist times, has also come to be seen as the "connectedness" of the "disconnected," e.g. quantum physics.

"... a performance (though more an activity than an action)."

Aristotle and many of his late modernist followers seem more focused on an action as a particular expression of a particular thought process. Social therapy focuses more on the activity (of either the individual or the group) than on the particularistic action.

\section{Endview}

The origin and evolution of social therapy over the decades has been humanitarian and, thereby, political. The philosophical conundrum it has dealt with- "What is going on in therapy that makes talking about one's inner life helpful when there is no such thing as an inner life?"- has contributed immeasurably to whatever effectiveness it has had in ameliorating privatized emotional pain and activating the human capacity to create development. We have come to understand that talking about one's inner life is therapeutic because and to the extent that it is a socially completive activity and not a 
transmittal of private states of mind, a performance and not a representation, a non-causal connection, a completion that is as ongoing as people choose to make it.

One of the formal functions of the social therapist is to say, "I think we have to stop." We think we have to stop. 


\section{References}

Baker, G. P., 1992. Some Remarks on "Language" and "Grammar," Grazer Philosophische Studien, 42, pp. 107-131.

Feldman, N. \& Silverman, B., 2004. “The let's talk about it model: Engaging young people as partners in creating their own mental health program" in K. E. Robinson (Ed), Advances in School-based Mental Health, Best Practices and Program Models. New Jersey: Civic Research Institute.

Holzman, L., 1997. Schools for Growth: Radical alternatives to current educational models. Mahwah, NJ: Erlbaum.

Holzman, L., 2006. Activating Postmodernism, Theory \& Psychology, 16(1), pp. 109123.

Holzman, L., 2009. Vygotsky at Work and Play. London and New York: Routledge.

Holzman, L,. 2010. "Without creating zpds there is no creativity" in C. Connery, V. John-Steiner and A. Marjanovic-Shane (Eds), Vygotsky and Creativity: A cultural-historical approach to play, meaning-making and the arts. New York: Peter Lang Publishers.

Hood [Holzman], L. \& Newman, F., 1979. The Practice of Method: An introduction to the foundations of social therapy. New York: Practice Press.

Lobman, C., 2005. "Yes And": The uses of improvisation for early childhood professional development, Journal of Early Childhood Teacher Education, 26, 3, pp. 305- 319 .

Lobman, C., 2010. “Creating developmental moments: Teaching and learning as creative activities" in C. Connery, A. Marjanovic-Shane and V. John-Steiner (Eds), 
Vygotsky and Creativity: A cultural-historical approach to play, meaning-making, and the arts. New York: Peter Lang Publishing.

Marx, K. \& Engels, F., 1974. The German Ideology. New York: International Publishers.

Massad, S., 2003. Performance of Doctoring: A philosophical and methodological approach to medical conversation, Advances in Mind-Body Medicine, 19(1), pp. $6-13$.

Newman, F., 2000a. "Does a story need a theory? (Understanding the methodology of narrative therapy)" in D. Fee (Ed), Pathology and the Postmodern: Mental illness in discourse and experience. Thousand Oaks, CA: Sage.

Newman, F., 2000b. "The performance of revolution (More thoughts on the postmodernization of Marxism)" in L. Holzman and J. Morss (Eds), Postmodern Psychologies, Societal Practice and Political Life [pp. 165-176]. New York: Routledge.

Newman, F., 2009. "Where is the magic in cognitive therapy? (A philo/psychological investigation)" in R. House and D. Loewenthal, (Eds), Against and for CBT: Towards a constructive dialogue? Ross-on-Wye, UK: PCCS Books.

Newman, F. \& Holzman, L., 1993. Lev Vygotsky: Revolutionary scientist. London: Routledge.

Newman, F. \& Holzman, L., 1997. The End of Knowing: A new developmental way of learning. London: Routledge.

Newman, F. \& Holzman, L., 1999. Beyond Narrative to Performed Conversation ('In the beginning' comes much later)", Journal of Constructivist Psychology, 12,1, pp. $23-40$. 
Newman, F. \& Holzman, L., 2006/1996. Unscientific Psychology: A culturalperformatory approach to understanding human life. Westport, CT: Praeger and iUniverse.

Salit, C.R., 2003. The Coach as Theatre Director, Journal of Excellence, 8.

Sabo, K., 2007. Youth Participatory Evaluation: Strategies for engaging young people. New York: Wiley.

van der Merwe, W. L. \& Voestermans, P. P., 1995. Wittgenstein's Legacy and the Challenge to Psychology, Theory \& Psychology, 5(1), pp. 27-48.

Vygotsky, L.S., 1978. Mind in Society. Cambridge, MA: Harvard University Press.

Vygotsky, L. S., 1987. The Collected Works of L. S. Vygotsky. Vol. 1. New York: Plenum.

Vygotsky, L.S., 2004. "The collective as a factor in the development of the abnormal child" in R.W. Rieber and D. K. Robinson (Eds), The Essential Vygotsky (pp. 201-219), New York: Kluwer Academic/Plenum Publishers.

Wittgenstein, L., 1953. Philosophical Investigations. Oxford: Blackwell.

Wittgenstein, L., 1965. The Blue and Brown Books. New York: Harper Torchbooks. 